\title{
The American Peace Corps Survey of the ocular complications of leprosy in South Korea: an evaluation and appraisal
}

\author{
T J FFYTCHE \\ St Thomas's Hospital, London
}

Accepted for publication 2 December 1983

\begin{abstract}
Summary The results of the American Peace Corps Survey of the ocular complications of leprosy in South Korea have been evaluated and compared with other surveys. Defective vision remains an important aspect of leprosy with $11 \%$ of the total number of 2925 patients examined having a visual acuity in both eyes of less than 6/60. It is hoped that the presentation of these figures will stimulate a more organized and rational approach to this difficult problem.
\end{abstract}

\section{Introduction}

In 1980 four American Peace Corps workers undertook an extensive survey of the ocular complications of leprosy in resettlement villages in South Korea. A total of 69 villages were visited and altogether 2925 patients were examined. The data collected was sorted and analysed with the aid of computer facilities at the American Embassy in Seoul. ${ }^{1}$ None of the participants in this survey had any formal medical training although all had received basic instruction in methods of examination of the eye. They were not therefore in a position to interpret the results of their survey from a medical standpoint, and it is my pleasure to undertake an evaluation and assessment of their study in this companion paper.

\section{Importance of the Survey}

The Peace Corps Survey is unique for three reasons: firstly for the number of patients in the study, secondly for the sample of the leprosy population, and lastly for the nature of the eye complications that occur in leprosy in South Korea. The conception of the survey itself and its success, despite the relative ophthalmic 
inexperience of the participants, makes this an important model for future projects. $^{2}$

The present survey is the second largest to be reported on ocular leprosy, being exceeded in numbers only by the Malawi study in which 8325 patients were examined. ${ }^{3}$ A less detailed study was carried out in India in 1978 when 2731 patients in mining areas were seen, ${ }^{4}$ but apart from this only 2 other surveys contain over a thousand patients-1279 in Brazil, ${ }^{5}$ and 1212 in Tanganyika. ${ }^{6}$ The largest survey previously reported in north-east Asia, where racial and environmental factors could be considered similar, is the study on 750 patients in Japan. ${ }^{7}$

Unlike many other surveys an attempt has been made to avoid bias in the selection of cases. Most studies in the past have been carried out in leprosaria where the majority of patients are the chronic sick and disabled, many of whom have advanced eye disease. Such reports are not representational of the leprosy population in general, and often concentrate only on those patients with overt ocular complications. By examining patients living in resettlement villages, regardless of whether they had ocular symptoms or not, the Peace Corps Survey has obtained information on a cross-section of the leprosy population, and the size of the sample $-10.4 \%$ of the total number of registered leprosy patients in South Korea - allows extrapolation of some of the results in terms of the disease in the whole country.

In carrying out the survey in South Korea the authors have selected a leprosy population particularly at risk from ocular damage, without the manifestations of eye involvement being influenced by other blinding diseases. The temperate climate combined with the high incidence of lepromatous leprosy in the Korean race are factors known to be associated with ocular complications. ${ }^{8}$ The economic status of the country has eliminated malnutrition and xerophthalmia as a cause of visual impairment, and the major blinding diseases of trachoma and onchocerciasis are not endemic in this area. As a result, eye symptoms and signs that develop in leprosy patients in South Korea are usually related to the disease itself, and can therefore be studied in the 'pure' form.

Another unique feature of the Peace Corps Survey is that the participants had received no formal medical training; but by the intelligent use of knowledge gained from instruction in the techniques of ocular examination, they were able to carry out a number of standardized subjective and objective tests on the patients in the study and thus provide data for analysis.

This achievement demonstrates that valuable information on ocular leprosy can be obtained by informed paramedical workers or medical students. It is of course admitted that some of the findings need more skilled medical interpretation, particularly those concerning the iris and lens, and that data on posterior segment involvement and non-leprotic disease is even less reliable. Even so, information produced by such a survey can be analysed with a fair degree of accuracy and the results compared with other studies carried out under similar conditions. $^{2}$ 


\section{Results}

A number of ophthalmic parameters were recorded in the survey and need individual assessment, although not all have an effect on visual function. The results are deficient in one aspect in that it is not possible to interrelate these parameters to derive information on the different causes of blindness, nor can the relationship between the various types of ocular complication be established. Despite this, much of the information is valuable and an attempt will be made to extract the data that is important and try to compare it with other studies. In many instances this is not possible because of the fundamental differences in the types of survey carried out and in the way the data is presented.

\section{TYPE OF LEPROSY}

Lepromatous leprosy occurred in $61 \%$ of the patients examined and tuberculoid in $25 \%$. This distribution of the type of leprosy conforms with the statistics provided by the Korean Ministry of Health and Social Affairs for the whole country-lepromatous $59 \%$ and tuberculoid $35.6 \%$, with the discrepancy in the tuberculoid figures accounted for by the relatively high proportion of cases whose status was unknown $(11 \%)$. These findings emphasize the preponderance of lepromatous leprosy in Asiatic races and are important since ocular complications are commoner in this form of the disease. In the Malawi survey, by comparison, tuberculoid leprosy was more frequent, occurring in $70 \%$ whereas the incidence of lepromatous leprosy was only $23 \%,{ }^{3}$ and similar ratios are seen throughout Africa. In India there is also a high frequency of tuberculoid leprosy - being seen in $53 \%$ in a survey in $1976^{9}$ with the lepromatous form occurring in only $16 \%$, and the interpretation of ocular complications in different countries should take these racial characteristics into account.

\section{AGE AND SEX DISTRIBUTION}

The age distribution of the patients in the survey is similar to that found in leprosy for the whole country with the majority of cases aged between 40 and 60 .

An interesting feature was the almost equal number of males and females examined. In most studies leprosy has been reported as commoner in males, ${ }^{10}$ and this is supported by the national statistics for South Korea where there is a male:female ratio of leprosy patients of $1 \cdot 5: 1$. The explanation for this discrepancy may lie in the composition of the resettlement villages which tend to be comprised of family units with the healthier and more able-bodied males remaining. Once an individual becomes severely affected by the disease a move to a leprosarium usually takes place and the distribution of male and female patients is more likely to reflect the general trend. Hobbs \& Choyce, for example, found a male:female ratio of $1 \cdot 5: 1$ in 507 patients in the Sunjei Buloh leprosarium in 
Malaysia. ${ }^{11}$ and a ratio of 2:1 was observed in over 500 patients in the Htauk-Kyant Hospital in Burma. ${ }^{12}$

The sample therefore represents a broad cross-section of the leprosy population in South Korea rather than the institutionalized cases, and since these patients are the ones who contribute to the daily running of the community, the effect of the disease on visual function and efficiency has a real importance both from an economic and social point of view.

\section{VISUAL ACUITY}

The most alarming finding in the survey was the high proportion of patients with severely impaired vision. $11 \%$ of the 2925 patients had a combined visual acuity of less than $6 / 60$ and were therefore functionally blind by Western standards. Blindness was commoner in males suggesting the higher susceptibility of the male patient to trauma because of working conditions. Resettlement villages are generally agricultural and male patients with defective lid closure or impaired corneal sensation who work outdoors are at greater risk from ocular trauma than similarly affected females who tend to stay indoors. Occupational hazards to the eyes of leprosy patients are therefore an important aspect of medical care and preventative measures to reduce them should be one of the prime objectives of medical and paramedical services.

It is not possible to analyse the different causes of blindness although experience from other studies on ocular leprosy in South Korea shows that the major complications result from corneal damage secondary to defective lid closure or from the late effects of chronic iritis. ${ }^{13}$ Figures for blindness elsewhere in the world vary considerably but present equally disturbing statistics: $13 \%$ in Ceylon, ${ }^{14} 7 \cdot 1 \%$ in Malaysia, ${ }^{11}$ whereas in Africa the overall incidence of blindness in leprosy is greatly reduced $-1.3 \%$ in Uganda $^{15}$ and $0.3 \%$ in Malawi. ${ }^{3}$ A straight comparison of these figures is difficult because of the differences in the way blindness is defined and in the sample of leprosy patients examined and analysed, most studies taking place in leprosaria.

\section{LID ABNORMALITIES}

Lid function was found to be affected in $25 \%$ of the eyes examined mostly in the form of ectropion or lagophthalmos. In an unpublished survey carried out in the Wilson Leprosy Centre in South Korea lid abnormalities were found even more frequently, with $37 \%$ of the patients having lagophthalmos with or without ectropion. ${ }^{16}$

Lid involvement in leprosy usually implies the presence of a VIIth nerve palsy which occurs in all forms of the disease. These figures are high compared with other studies and the incidence of lid changes are reported as much less in Africa, with only $3 \%$ of the patients in the Malawi survey affected ${ }^{3}$ and $6 \%$ in Uganda. ${ }^{15}$ 
Elsewhere in the world the figures for facial nerve palsy vary considerably, being as high as $27 \%$ in Vietnam, ${ }^{17} 21 \%$ in Israel, ${ }^{18} 13 \%$ in Brazil, ${ }^{19}$ and $7 \%$ in Turkey. ${ }^{20}$

\section{CORNEAL DISEASE}

Corneal involvement is also a major complication of ocular leprosy in all forms of the disease. It results either from primary infection, although the changes from the superficial stromal keratitis that occurs in lepromatous leprosy seldom cause severe visual symptoms, ${ }^{21}$ or more commonly the cornea develops scarring secondary to impaired sensation and defective lid closure. In many tropical countries corneal disease arising from non-leprosy causes is added to the damage from leprosy. As expected, blinding corneal lesions were commoner in males and occurred in over $5 \%$ of the patients examined. $11 \%$ of all eyes in the survey had some sort of corneal opacity and in at least $20 \%$ the corneal sensation was either absent or impaired. No statement can be made on the relationship between corneal opacification and loss of sensation, nor on the relative incidence of the different forms of the disease, but similar studies elsewhere have shown a variable degree of corneal involvement with $23 \%$ affected in the Wilson Leprosy Centre Survey, ${ }^{16} 17 \%$ in Malawi, ${ }^{3}$ whereas only $8 \%$ of 750 patients in Japan were affected ${ }^{7}$ and in Tanganyika the incidence of corneal damage was reduced to $5 \%{ }^{6}$ Again this regional difference is difficult to explain and suggests that a number of factors are responsible.

\section{IRIS ABNORMALITIES}

The cause of blindness in all forms of leprosy is shared equally between corneal scarring and the results of intraocular disease affecting the iris and lens. Acute iritis may occur in patients with all forms of leprosy, often accompanying a change in polarity either spontaneous or related to treatment as part of the lepra reaction. ${ }^{11}$ Chronic iritis occurs in lepromatous leprosy and is responsible for progressive atrophy of the iris and increasing miosis which reduces visual acuity especially in the presence of corneal or lenticular changes. ${ }^{22}$

The early signs of chronic iritis are often difficult to diagnose without the aid of a slit-lamp and are frequently missed since they may not be accompanied by any symptoms. As the condition progresses clinical signs become more evident and these include a decrease in the size of the pupil and, if synechiae are present, a distortion of its shape. There is a corresponding reduction in the amplitude of the light reflex and the end-result is a small unreacting pupil through which very little light can be transmitted. The Peace Corps Survey was not equipped to distinguish or differentiate the early changes of chronic iritis, but the measurement of pupil size, shape and reactions gives some indication of iris involvement and at least $20 \%$ of all eyes examined showed some abnormality. Figures derived from other studies show a considerable variation with $76 \%$ of lepromatous patients in a study 
in Iran showing iris involvement, ${ }^{23}$ and $47 \%$ of the Wilson Leprosy Centre Survey were similarly affected $;{ }^{16}$ by contrast only $7 \%$ of lepromatous cases in Malawi had iris disease, ${ }^{3} 6 \%$ in $\operatorname{Japan}^{7}$ and $3 \%$ of all cases in the Uganda survey. ${ }^{15}$

\section{LENS CHANGES}

In the more posterior parts of the eye examination techniques become difficult unless sophisticated instruments are available. For this reason the assessment of cataract by the Peace Corps Survey was inaccurate, partly because of the lack of experience of the participants but also because in a large number of patients the pupil aperture was too small to allow an adequate assessment of the state of the lens. This problem cannot be easily resolved even with access to the slit-lamp and ophthalmoscope as it is not usually possible to dilate pupils affected by chronic iritis. ${ }^{24}$ No firm conclusions can therefore be drawn on the presence or absence of lens opacities except to note that cataract has been reported as a common secondary complication of chronic iritis in lepromatous leprosy. $25,19,26$

\section{Discussion}

The results of the American Peace Corps Survey in South Korea throw an important light on the nature of eye complications in a country where leprosy is still endemic and where racial and environmental factors combine to encourage the development of ocular involvement. Eyes that are affected are in addition unlikely to be subjected to other major causes of blindness so that the Korean leprosy population presents a 'pure' form of ocular disease. The results confirm that ophthalmic complications are a fundamental aspect of the condition and that therapy directed towards their prevention and treatment is of paramount importance.

The figures of vision less than $6 / 60$ in both eyes in $11 \%$ of this cross-section of the leprosy community are alarmingly high by any standards and need urgent attention. Preventive measures to protect the eyes particularly with reference to occupation should form a basic aspect of leprosy health care and education. Such measures would go a long way towards reducing the amount of corneal damage and preventing opacification. The treatment of chronic iritis presents a greater problem since it is often very difficult to diagnose in the early stages as it is usually asymptomatic. It requires supervision of leprosy patients, particularly those with the lepromatous form of the disease, by ophthalmologists equipped with the slit-lamp; and although conventional therapy may not always be effective, secondary complications could be detected early and the necessary surgical procedures instituted. Most patients with chronic iritis eventually require surgery, either for optical iridectomy or lens extraction, and this can be carried out as a non-urgent procedure at selected centres. The simple creation of eye 
clinics in regional centres which could be attended on a regular basis by qualified ophthalmologists would therefore be a valuable development in the management of eye complications in a country such as South Korea where the problem of leprosy is so extensive.

The comparison of findings in this survey with studies undertaken elsewhere in the world demonstrates the variable incidence and nature of ocular complications and stresses the importance of epidemiological studies in the detection of those factors which predispose to ocular damage.

The significance of the American Peace Corps Survey is that by its simple conception it can act as a model for future surveys in different countries to identify those areas where there is a need for ophthalmic supervision both for the individual leprosy patient and for the leprosy community as a whole.

\section{Acknowledgments}

I am grateful to the Wilson Leprosy Centre, Suncheon, South Korea and to LEPRA for enabling me to be associated with this project.

\section{References}

${ }^{1}$ Courtright P, Green R, Pilarski R, Smucny J. A survey of the eye complications of leprosy in South Korea. Lepr Rev, 1984; 55: 229-237

2 ffytche TJ. A computer form to aid in the collection of data on the ocular complications of leprosy. Lepr Rev, 1983; 54: 271-81.

3 Ticho V, Ben Sira I. Ocular leprosy in Malawi. Brit J Ophthalmol, 1970; 54: 107-12.

${ }^{4}$ Acharya RP. Ocular involvement in leprosy. (A study in mining areas in India.) Ind $J$ Ophthalmol, 1978; 26: 21-4.

${ }^{5}$ de Barros M. The ocular complications of leprosy. Amer J Ophthalmol, 1946; 29: 162-9.

${ }^{6}$ McLaren DS, Shaw MJ, Dalley KR. Eye disease in leprosy patients. A study in central Tanganyika. Int J Lepr, 1961; 29: 20-8.

7 Suzuki T. Ocular complications of leprosy in Japan. Folia Ophthalmol Jpn, 1980; 31: 1719-27.

${ }^{8}$ Cochrane RG. Leprosy in Korea. Lepr Rev, 1956; 27: 1-19.

9 Sehgal VN, Aggarwal DP, Sehgal N. Ocular leprosy. Ind J Med Res, 1976; 64: 160-8.

${ }^{10}$ Holmes WJ. The eyes in leprosy. Trans Ophthalmol Soc, UK 1961; 81: 397-420.

${ }^{11}$ Hobbs HE, Choyce DP. The blinding lesions of leprosy. Lepr Rev, 1971; 42: 131-7.

12 Kan Nyunt, ffytche TJ. Ocular complications of leprosy in Burma. In preparation.

13 ffytche TJ. The role of iris changes as a cause of blindness in lepromatous leprosy. Brit $J$ Ophthalmol, 1981; 65: 231-9.

14 Weekeroon L. Ocular leprosy in Ceylon. Brit J Ophthalmol, 1969; 53: 457-65.

15 Emiru VP. Ocular leprosy in Uganda. Brit J Ophthalmol, 1970; 54: 740-3.

16 Rock R, Obara A, Amundsen AM. Report of an ophthalmological survey of Colony patients at the Wilson Leprosy Centre. 1973.

17 Hornblum A. Ocular leprosy in South Vietnam. Amer J Ophthalmol, 1973; 75: 478-80.

18 Landau J, Gabbay A. Ocular leprosy in Israel. Acta med Orient, 1955; 14: 129-33. 


\section{T J ffytche}

19 Shields JA, Waring GO, Monte LG. Ocular findings in leprosy. Amer J Ophthalmol, 1974; 77: 880-90.

${ }^{20}$ Slem G. Clinical studies of ocular leprosy. Amer J Ophthalmol, 1971; 71: 431-4.

${ }^{21}$ Allen JH, Byers JL. The pathology of ocular leprosy. 1. Cornea. Arch Ophthalmol, 1960; 64: 216-20.

22 ffytche TJ. The eye and leprosy. Lepr Rev, 1981; 52: 111-19.

${ }^{23}$ Ramanujam K, Sundar PR, Khamnei AA. Ocular leprosy in Iran. Survey at the Baba Baghi Leprosarium, Tabriz. Lepr Rev, 1978; 49: 231-9.

24 de Barros M. A clinical study of leprous iritis. Int J Lepr, 1940; 8: 353-60.

25 Choyce DP. The diagnosis and management of ocular leprosy. Brit J Ophthalmol, 1969; 53: 217-23.

${ }^{26} \mathrm{ffytche}$ TJ. Cataract surgery in the management of the late complications of lepromatous leprosy in South Korea. Brit J Ophthalmol, 1981; 65: 243-8. 